\title{
DNA Sequencing by Capillary Electrophoresis Using Short Oligonucleotide Primer Libraries
}

BioTechniques 20:1058-1069 (June 1996)

M.C. Ruiz-Martinez,

E. Carrilho, J. Berka, J. Kieleczawa ${ }^{1}$, A.W. Miller, F. Foret, S. Carson and B.L. Karger

Northeastern University, Boston, MA, and ${ }^{1}$ Brookhaven National Laboratories, Upton, NY, USA

\section{INTRODUCTION}

Fast separation methodologies are being developed for large-scale DNA sequencing, e.g., capillary electrophoresis (CE) (16) and ultrathin slab gels $(4,33)$. The inherent properties of CE-short analysis times and ease of automation-are well-suited to sequencing $(3,22,30)$. Furthermore, the throughput using single capillary instruments can be potentially increased through multiple capillary array instruments $(15,24,28)$. Cross-linked, gelfilled capillaries have been used to obtain size-dependent separation of DNA sequencing fragments $(3,7,11)$. Although extended sequences have been obtained with such matrices (1), these materials can be disadvantageous in CE because of potentially poor gel stability.

Our laboratory introduced the use of low-viscosity, replaceable linear polyacrylamide (LPAA) solutions for the separation of sequencing reaction products (30). Recently, other polymer solutions have been used for DNA sequencing as well $(8,9)$. The relatively low viscosity of these solutions permits replacement of the sieving matrix after each run, thus providing extended column lifetime, speed of separation and ease of automation. Previously, we reported the use of LPAA solutions to obtain sequencing information up to 350 bases in $30 \mathrm{~min}$ (30). These polymer solutions were optimized to provide robust separation of short stretches of sequences in a minimum analysis time, using a simple two-peak height-twocolor base coding.

The strategy frequently used for large-scale operations is shotgun sequencing, mainly because this approach is well-suited to automated instruments $(13,37)$. However, there are drawbacks to this approach: its tedious and laborious subcloning steps, high redundancy (5-8 per base pair) and timeconsuming manual sequence editing.

Directed sequencing strategies provide potential advantages over shotgun procedures, i.e., higher efficiency (a larger number of bases read per unit of time), less redundancy, fewer cloning steps and straightforward data assembly (36). The sequencing information obtained from the initial sequencing analysis, starting from the known sequence (e.g., a cloning vector), is used to determine the priming site for a second sequencing reaction. Primer-walking methods have been applied to largescale sequencing projects with some success (32).

The lack of automated procedures and the necessity for synthesis of new primers for each reaction have limited the routine application of primer walking, in spite of its higher sequencing efficiency (23). In comparison to typical slab-gel operation, the increased separation speed and ease of automation offered by CE provide significant potential for the development of a closed loop instrument based on primer walking. However, custom synthesis of oligonucleotides 18-20 bases in length is generally expensive and slow. 
Table 1. Purification of Sequencing Products from SSB-Hexamer Primed Reactions

Digest tsSSB-1 protein by adding $2 \mu \mathrm{L}$ of $2 \mu \mathrm{g} / \mu \mathrm{L}$ pronase and $1.3 \mu \mathrm{L}$ of $10 \%$
(wt/vol) SDS to the sequencing reaction. The digestion reaction is performed at
$65^{\circ} \mathrm{C}$ for $20 \mathrm{~min}$.

Prepare a Sephadex ${ }^{\circledR}$ (Pharmacia Biotech) microcolumn (CentriSep ${ }^{\mathrm{TM}}$; Princeton Separations, Adelphia, NJ, USA) according to the manufacturer's specifications.

After digestion, transfer the sequencing reaction mixture onto the top of the Sephadex column.

Centrifuge the microcolumn for $4 \mathrm{~min}$ at $3000 \mathrm{rpm}$, collect the sample and vacuum dry under centrifugation.

Resuspend the sample in $40 \mu \mathrm{L}$ of dimethyl sulfoxide (DMSO) for $30 \mathrm{~min}$. Wash an ultrafiltration microcolumn (300000 molecular weight cutoff) (UltrafreeMC; Millipore, Bedford, MA, USA) extensively with water, centrifuging at 5000 rpm for $5 \mathrm{~min}$. Pipet $40 \mu \mathrm{L}$ of DMSO onto the microcolumn, then centrifuge for 5 min at $5000 \mathrm{rpm}$ in a fixed-angle microcentrifuge (Model 5415C; Eppendorf North America, Madison, WI, USA). Discard the DMSO spun through.

Heat the sample dissolved in DMSO for 5 min at $95^{\circ} \mathrm{C}$.

Place the heated solution on the microcolumn and heat for an additional $5 \mathrm{~min}$ at $100^{\circ} \mathrm{C}$.

Spin the column for $5 \mathrm{~min}$ at $5000 \mathrm{rpm}$. The recovered purified sample is injected electrokinetically into the capillary column for $10 \mathrm{~s}$ at a constant electric field of $200 \mathrm{~V} / \mathrm{cm}$.

Several reports (for example, Reference 26) have presented faster and smaller scale synthesis of oligonucleotides compared to traditional methods. However, these approaches are not fully sufficient for large-scale sequencing.

In 1989, the strategy of primer walking using a finite size oligonucleotide library was introduced (34). It was later shown that strings of contiguous hexamers, in combination with singlestranded binding protein (SSB)-saturated templates, can prime sequencing reactions efficiently (i.e., sufficient sequencing products for detection) and specifically, using both radioactivity and fluorescence detection with either single- or double-stranded templates $(17,25)$. A related strategy for directed sequencing has also been reported based on the use of modified modular primers (heptamers and pentamers) without SSB $(18,19)$. This general approach (i.e., the use of short oligonucleotides as primer for DNA sequencing reactions) is seen as a possible cost-effective, closed-end system for large-scale sequencing.

This paper presents the results on the first successful application of sequencing chemistries using short oligonucleotide libraries and CE analysis in a single capillary prototype instrument using replaceable polymer solutions. DNA sequencing reactions were performed on M13mp18 template with fluorescence-labeled dideoxynucleotides (Applied Biosystems PRISM $^{\text {TM }}$ T-7 dye-labeled dideoxy terminators [Perkin-Elmer/Applied Biosystems Division (PE/ABI), Foster City, CA, USA]) for Sequenase ${ }^{\circledR}$ Version 2.0 [United States Biochemical (USB), Cleveland, OH, USA] and analyzed by $\mathrm{CE}$ using replaceable linear polyacrylamide matrices (LPAA). The fast analysis of the sequencing fragments in $\mathrm{CE}$ provides an overall increase in sequencing speed. A CEbased automated sequencer, utilizing modular primer walking, should provide complementary technology to automated shotgun sequencing strategies for large-scale sequencing efforts.

\section{MATERIALS AND METHODS}

\section{Instrument Description}

The basic design of a CE instrument using a single laser line excitation (argon ion laser $488 \mathrm{~nm}$ ) and two photomultipliers (PMT) for on-column fluorescence detection of sequencing reaction products has been described previously (30). The instrument described in this paper differs only in the detector and the capillary column heating device. The detector is an intensified photodiode array instrument (Model 1420; EG\&G Princeton Applied Research, Princeton, NJ, USA) for full spectral detection of labeled dideoxynucleotides (5). The thermostat on the heating device regulates the temperature of the separation column, providing constant temperature (e.g., $30^{\circ} \pm$ $0.5^{\circ} \mathrm{C}$ ) for $15 \mathrm{~cm}$ of the effective length of the capillary. A $15-\mathrm{cm}$ piece of copper tubing is filled with heat-conductive epoxy (Norlabs, Greenwood, CT, USA) and wrapped with a flexible heating element equipped with a thermistor connected directly to a temperature controller (Omega Engineering, Stamford, CT, USA). The remaining segment of the capillary is left unheated due to physical limitations.

The data are recorded in two formats: acquisition of the full spectra and real-time monitoring of the signal at two pre-selected diode groups. The schematic of the data-acquisition system has been published previously (5). Stored data are analyzed with the aid of the laboratory-developed software, which allows viewing of the four-color dye channels, spectral information, base calling, etc.

\section{Base-Calling Software}

The raw spectra were first smoothed using principal component analysis, which also reduced the data to a compact form for manipulation. Color separation was then achieved by solving a matrix equation by ordinary linear regression, $\widetilde{\mathbf{Y}}=\widetilde{R} \widetilde{\mathbf{C}}$, where $\tilde{Y}$ is the matrix of raw data, $\tilde{\mathrm{R}}$ a matrix containing the four dye-terminator spectra and $\widetilde{\mathbf{C}}$ the solution matrix, a four-channel electropherogram in which each channel is the fluorescence signal of one of 
Table 2. Hexamer Primers Used for Sequencing on M13mp18

\begin{tabular}{|c|c|c|c|c|c|}
\hline $\begin{array}{l}\text { Reaction } \\
\text { No. }\end{array}$ & $\begin{array}{l}\text { Sequence Hexamer \#3 } \\
\text { ( } 5^{\prime} \text { End of the Primers) }\end{array}$ & $\begin{array}{c}\text { Sequence Hexamer \#2 } \\
\text { (Middle Hexamer) }\end{array}$ & $\begin{array}{r}\text { Sequence Hexamers \#1 } \\
\left(3^{\prime} \text { End of the Primers) }\right.\end{array}$ & $G+C$ & $\begin{array}{l}3^{\prime} \text { End Position } \\
\text { on M13mp18 }\end{array}$ \\
\hline 1 & АACTCC & AACAGG & TCAGGA & 9 & 291 \\
\hline 2 & GGCATA & GTAAGA & GCAACA & 8 & 639 \\
\hline 3 & TTTTAA & GAACTG & GCTCAT & 6 & 806 \\
\hline 4 & GCAACG & GCTACA & GAGGCT & 11 & 1324 \\
\hline 5 & CACCAG & TACAAA & CTACAA & 7 & 1760 \\
\hline 6 & GTTTTA & ACGGGG & TCAGTG & 9 & 2106 \\
\hline 7 & ATTCAT & ATGGTT & TACCAG & 6 & 2714 \\
\hline 8 & CCACAA & GAATTG & AGTTAA & 6 & 3004 \\
\hline 9 & GAATCA & TTACCG & CGCCCA & 10 & 3405 \\
\hline 10 & GCTCAA & CAGTAG & GGCTTA & 9 & 3752 \\
\hline
\end{tabular}

the four dyes. The matrix $\tilde{\mathrm{R}}$ was obtained by searching the most intense spectra in the raw data for the best matches to the reference spectra of the four dye terminators. After color separation, noise was removed by Wiener filtering (27). Baseline correction was then performed by subtracting from each point the smallest value in a short interval on adjacent sides.

After this initial processing, peak detection and base calling were performed concurrently with a moving time window containing about ten bases at any moment. Peaks were determined as maxima in the data that matched a model of peak height, shape and spacing. Since these parameters changed with migration time, each called peak was used to update the model. Calls were made by a graphtheoretic method, which determined the most evenly spaced set of peaks (after dye mobility correction), with due consideration given to peak height and width (2). Sequencing was terminated when irregularity in peak spacing increased above an arbitrary threshold, indicating unreliable calls.

\section{Capillary Coating and Sieving Matrix Preparation}

The capillaries were coated to suppress the electroendoosmotic flow and to provide high separation efficiency, as described (12). Absence of electroendoosmotic flow also improves both reproducibility and ruggedness of the electrophoretic separation. The sieving matrix (4\% T/1× TBE/30\% [wt/vol] formamide/3.5 $\mathrm{M}$ urea) was developed to extend the sequence readout per run in a reasonable analysis time over that previously published (30). A separate paper will present the optimization of LPAA solutions for the separation of single-stranded DNA fragments. The synthesis of LPAA solutions was performed using the conventional ammonium persulfate $/ N, N, N^{\prime}, \mathrm{N}^{\prime}$-tetramethylethylenediamine (APS-TEMED) redox system. The polymer was elongated by using small amounts of both radical initiator and catalyst and a low polymerization temperature $\left(0^{\circ} \mathrm{C}\right)$ to provide high molecular weight LPAA polymer fibers. Since oxygen is a radical quencher, an inert atmosphere must be provided for the polymerization reaction.

In brief, $1 \mathrm{~mL}$ of acrylamide solution $(4 \%$ acrylamide $[\mathrm{wt} / \mathrm{vol}]$ in TBEbuffer [1× Tris/boric acid/ethylenediaminetetraacetic acid, $\mathrm{pH} 8.3$ ]; $30 \%$ $\mathrm{wt} / \mathrm{vol}$ formamide; $3.5 \mathrm{M}$ urea) was degassed for $2 \mathrm{~h}$ by purging with helium. With a microsyringe, $1 \mu \mathrm{L}$ each of $10 \%$ TEMED and $10 \%$ APS was added to the sealed vial. After briefly vortex mixing, the polymerization was carried out in an ice bath $\left(0^{\circ} \mathrm{C}\right)$ for $24-48 \mathrm{~h}$. After polymerization, the sieving matrix was kept in the freezer $\left(-20^{\circ} \mathrm{C}\right)$ to avoid decomposition of the buffer denaturants. Care must be exercised to avoid exposure of the polymer solutions to room temperature for pro- longed time. (Note: Formamide can rapidly decompose in basic solution at room temperature.)

The separation performance and reproducibility of the capillary system were determined using a FAM-labeled (-21) primer (PE/ABI) and M13mp18 ssDNA template (New England Biolabs, Beverly, MA, USA), and the sequencing reaction was terminated with dideoxythymidine triphosphate (ddTTP) (USB). These reactions were prepared according to the USB Sequenase protocol, with the exception that the labeling step was omitted and the $\mathrm{dNTP} / \mathrm{ddNTP}$ ratio in the extension/termination was changed to 400 from typically $10-50$.

\section{Sequencing Reaction Protocol}

Two main strategies were used for DNA sequencing using short oligonucleotide primers and labeled dideoxynucleotides: (i) hexamers with single-stranded binding protein temperature-sensitive mutant ( $t s \mathrm{SSB}$-1, made available to Brookhaven National Laboratories by courtesy of C.W. Fuller, Amersham Life Sciences Inc.)-saturated templates and (ii) modified modular primers. For these studies, the DNA sequencing samples using modified modular primers were kindly provided by L. Kotler and L. Ulanovsky of the Weizmann Institute in Israel. A protocol previously reported was followed $(18,19)$. 
The protocols for DNA sequencing using hexamers and SSB-saturated templates with both radioactivity $(0.7$ $\mu \mathrm{g}$ of M13mp18) and fluorescence detection ( $2 \mu \mathrm{g}$ of M13mp18) have also been reported previously $(17,25)$. The protocol used in this work was slightly modified by using $t s \mathrm{SSB}-1$ and including $1 \%(\mathrm{wt} / \mathrm{vol}$ ) sodium dodecyl sulfate (SDS) in the digestion reaction. The use of SDS with pronase improved the proteolytic digestion of $t s$ SSB-1 (31).
In addition, the concentration of NANddG in the PRISM T-7 mixture was increased from $8.0 \mu \mathrm{M}$ to $13.0 \mu \mathrm{M}$ by the addition of NAN-ddG to compensate for the poor excitation of the NAN dye (maximum absorption at $555 \mathrm{~nm}$ ) by the 488-nm line of the argon ion laser. The amount of template DNA used per reaction was the same as previously described (25). In future work, a tunable dye laser will be used to compensate for the poor excitation of NAN and al-

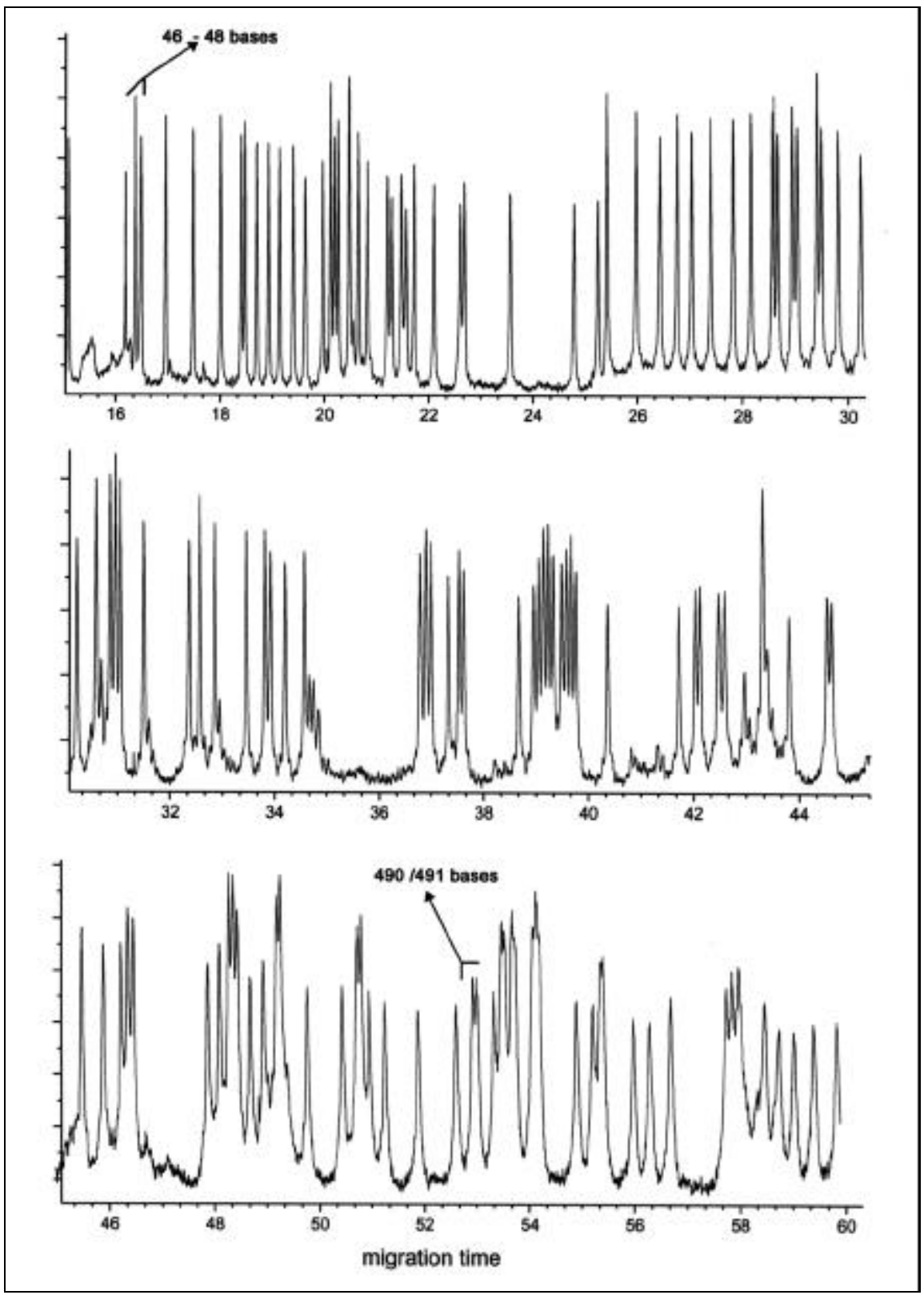

Figure 1. Separation of FAM-labeled primer (-21) sequencing reaction products from M13mp18 terminated with dideoxythymidine triphosphate. The electrophoretic conditions were the following: capillary effective length $=30 \mathrm{~cm}$ (total length $=40 \mathrm{~cm}$ ); column temperature $25^{\circ} \mathrm{C}$; sieving matrix $4 \% \mathrm{~T}$ LPAA $/ 30 \%$ (wt $/ \mathrm{vol}$ ) formamide $/ 3.5 \mathrm{M}$ urea; constant electric field $=200 \mathrm{~V} / \mathrm{cm}$. 
Table 3. Sequencing Results on M13mp18 Using SSB-Hexamer Primed Reactions and Capillary Electrophoresis Analysis

\begin{tabular}{|c|c|c|c|c|c|}
\hline $\begin{array}{l}\text { Primer } 3^{\prime} \text { End Site } \\
\text { on M13mp18 }\end{array}$ & $\begin{array}{l}\text { Site On M13mp18 for } \\
\text { the First Base Sequenced }\end{array}$ & $\begin{array}{l}\text { Site On M13mp18 for } \\
\text { the Last Base Sequenced }\end{array}$ & $\begin{array}{l}\text { Total Number of } \\
\text { Bases Sequenced }\end{array}$ & Miscalls & $\begin{array}{c}\% \\
\text { Accuracy }\end{array}$ \\
\hline 291 & 253 & 7165 & $337 a$ & 8 & 97.6 \\
\hline 639 & 603 & 144 & 459 & 11 & 97.6 \\
\hline 806 & 775 & 202 & $573^{b}$ & 6 & 99.0 \\
\hline 1324 & 1281 & 868 & 413 & 4 & 99.0 \\
\hline 1760 & 1703 & 1251 & 452 & $24 c$ & 94.0 \\
\hline 2106 & 1998 & 1598 & 400 & 11 & 97.3 \\
\hline 2714 & 2676 & 2181 & 495 & 8 & 98.4 \\
\hline 3004 & 2972 & 2540 & 432 & 3 & 99.3 \\
\hline 3752 & 3704 & 3188 & 516 & 13 & 97.5 \\
\hline & & & $\begin{array}{l}\text { av. number } \\
\text { of bases } \\
\text { sequenced }\end{array}$ & $\begin{array}{l}\text { av. number } \\
\text { of miscalls }\end{array}$ & accuracy \\
\hline & & & 456 & 10 & $97.8 \%$ \\
\hline \multicolumn{6}{|c|}{$\begin{array}{l}\text { aThe short read length was due to weak signal from this sample. } \\
\text { bThe highest priming efficiency of the sites tested. } \\
\text { cThe number of errors was higher than the average because of mispriming. }\end{array}$} \\
\hline
\end{tabular}

low for the use of the regular PRISM $\mathrm{T} 7$ mixture. Increasing the NAN-ddG concentration in the deoxynucleotide-dideoxynucleotide mixture increased the probability for reaction termination with the ddG terminator. Since the intensity of the fluorescence signal was dependent on both excitation efficiency and concentration, the signal increased.

\section{Purification of Sequencing Reaction Products}

Electrokinetic injection was required to introduce the sequencing fragments into the capillary column. To maximize the signal, small ions, nonincorporated deoxynucleotides and dideoxynucleotides, hexamer primers, template DNA and $t s \mathrm{SSB}-1$ digestion products were removed from the sample. Maximum signal was required to accommodate hexamers from weak priming sites. The presence of SSB protein molecules in the sequencing sample interfered with both the injection and separation of sequencing fragments in CE. The use of a temperaturesensitive mutant $t s \mathrm{SSB}-1$ was necessary to purify the sequencing sample for $\mathrm{CE}$ analysis. The DNA-protein complex between $t s \mathrm{SSB}-1$ and the template DNA is disrupted above $47^{\circ} \mathrm{C}$
(21). Therefore, at the temperature of $65^{\circ} \mathrm{C}$, pronase could effectively digest the protein into short peptides or amino acid components. The detailed purification method for DNA sequencing of samples using hexamer-SSB chemistry and CE analysis is outlined in Table 1. Investigations are ongoing on automated procedures for sample purification.

\section{RESULTS AND DISCUSSION}

\section{Capillary Electrophoretic Separation of Sequencing Reaction Products with 4\% T LPAA Sieving Matrix}

In our previous work, a $6 \%$ T LPAA matrix was used for the separation of sequencing fragments of at least 350 bases in $30 \mathrm{~min}(30)$. The synthesis and electrophoretic conditions were optimized to obtain fast sequencing analysis of short stretches of DNA using simple instrumentation. In order to extend the read length to 450-500 bases, a lower concentration of LPAA was selected $(4 \% \mathrm{~T})$. To achieve sufficient separation efficiency, the polymerization parameters were optimized to synthesize LPAA of high molecular weight. Such LPAA can be synthesized by means of the conventional redox ini- tiation process (APS and TEMED) by decreasing the polymerization temperature and by decreasing the amount of radical initiator used (14). The average molecular weight for the laboratorysynthesized LPAA (4\% T) was determined by size-exclusion chromatography to be approximately $10^{6} \mathrm{Da}$ with polydispersity of 2.2 (American Polymer Standards, Mentor, OH, USA).

The use of $4 \% \mathrm{~T} / 1 \times \mathrm{TBE} / 30 \%$ (wt/vol) formamide/3.5 M urea LPAA with coated capillaries allowed separation to base 500 in roughly $60 \mathrm{~min}$. As an example, Figure 1 presents the electropherogram for the separation of a M13mp18-FAM-labeled primer (-21) sequencing reaction terminated with ddTTP. Using this LPAA solution, sequencing fragments ranging in size from 27 bases to 498 bases could be resolved by one base difference in 53 minutes.

\section{Optimization of Sample Purification and Injection}

The amount of DNA sequencing reaction products injected into the column and the degree of separation affect both the read length and the accuracy of the base calls. Sequencing chemistries, based on the use of short oligonucleotides as primers in combination 


\section{Research Reports}
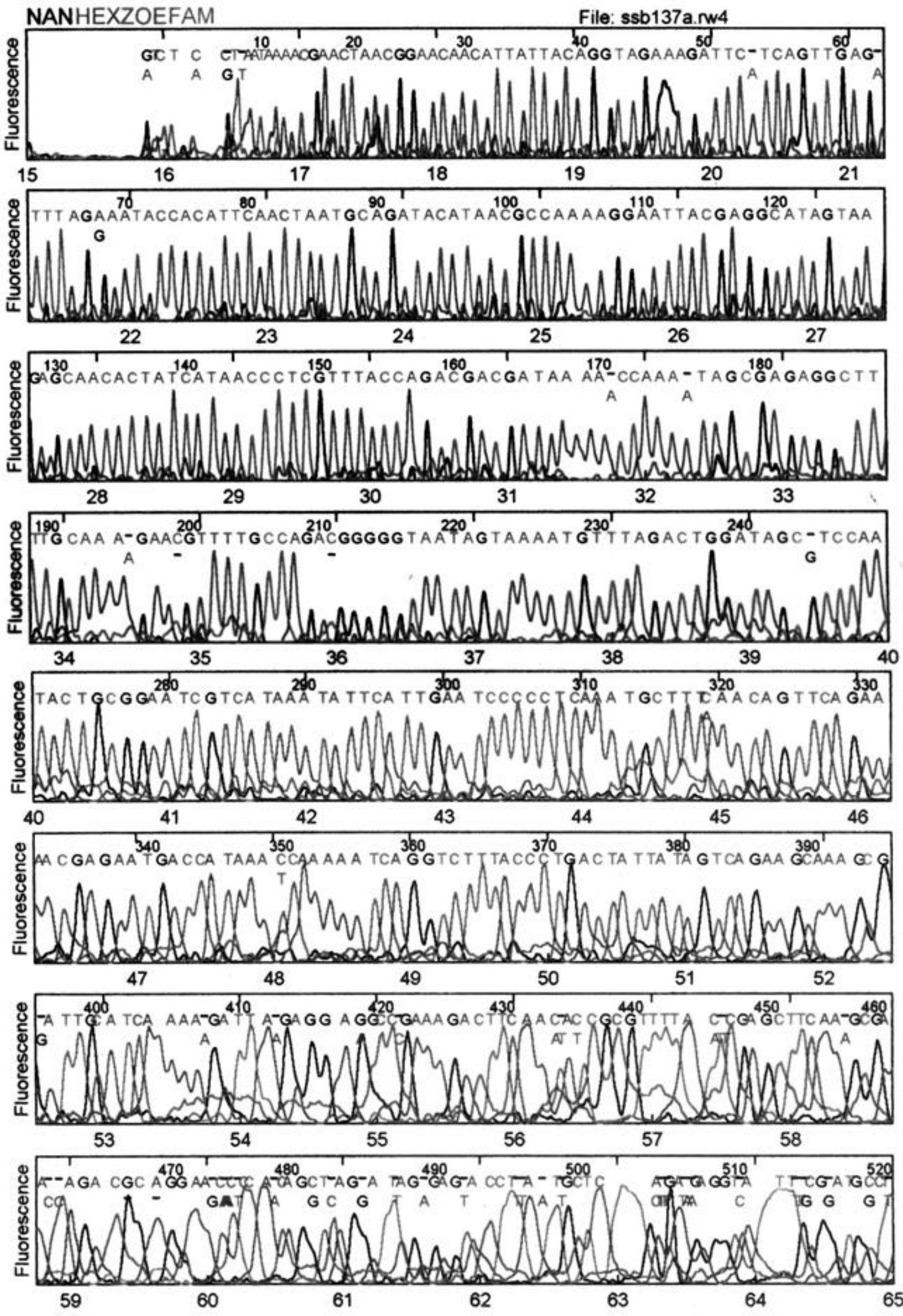

Figure 2. Separation of SSB-hexamer primed sequencing reaction products. The electrophoretic conditions were the same as for Figure 1 except that the temperature was $30^{\circ} \mathrm{C}$. The reaction was primed at position 3' 806 in M13mp18 with three hexamers and $6.5 \mu \mathrm{g}$ of $t s \mathrm{SSB}-1$. 


\section{Research Reports}

NANHEXZOEFAM File: lev522.rw4


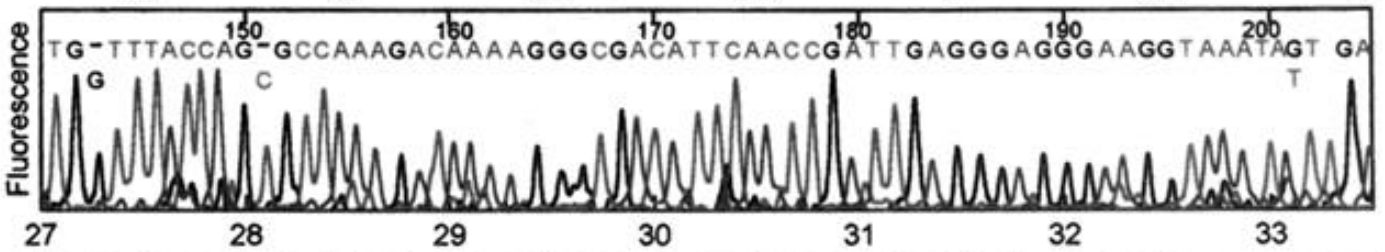





Figure 3. Separation of modified modular primed sequencing reactions products. The electrophoretic conditions were the same as for Figure 2 . The primers used for this reaction were three degenerate, phosphorylated heptamers and one pentamer at position 3'2892 on M13mp18. 
with dye-labeled dideoxynucleotides, in general yielded lower amounts of products than other sequencing chemistries, e.g., labeled primers or cycle-sequencing. Furthermore, the signal using short primers could differ as much as 50-fold, depending on the priming site or the template. The use of these novel sequencing chemistries thus required maximization of the amount of purified material introduced in the capillary column. The electrokinetic injection of sequencing fragments was optimized and will be described in a separate report.

The use of labeled dideoxynucleotides, large quantities of hexanucleotides $(\mu \mathrm{M})$ and SSB protein $(\mu \mathrm{g})$ imposed unusual conditions for the purification of sequencing fragments. A two-step purification process was designed to eliminate impurities. The salts and SSB digestion products were removed with a MicroSpin Sephadex ${ }^{\circledR}$ column (Pharmacia Biotech, Piscataway, NJ, USA) and the template DNA was removed by ultrafiltration in a denaturant solvent. As a result of these purification steps, long injection times (20 s) could be used without significant loss in current or separation. Loss of current or column failure is frequently found to be caused by template present in the sample $(29,35)$.

\section{Sequencing Results on M13mp18 SSDNA}

Sequencing using single-stranded binding protein-saturated templates and hexamer primers

Templates saturated with E. coli SSB protein have been used for sequencing to minimize the secondary structure of the DNA template and increase the processivity of DNA polymerase (Sequenase Version 2.0) (20). SSB protein has also been utilized in hexamer string sequencing to improve the specificity of short oligonucleotides annealing to the template (17). The presence of the SSB protein in the sequencing sample, however, interfered with both the separation and injection of sequencing products. The use of the $t s \mathrm{SSB}-1$ mutant offers great advantage for the application of this chemistry to
CE. In order to remove the $t s \mathrm{SSB}-1$ from the sequencing sample, pronase was used to digest the protein at $65^{\circ} \mathrm{C}$. $t s \mathrm{SSB}-1$ proteins allowed for the proteolytic digestion upon dissociation of the DNA-protein complex in the sequencing sample $(6,25)$. It is noteworthy that no sequencing ladders could be detected when the wild-type SSB was utilized for the sequencing reactions (results not shown).

The optimized purification scheme was then applied to SSB-hexamer primed reactions, and the reaction products were analyzed by CE. Figure 2 shows an example of the separation of sequencing fragments starting at site 3' 806 on M13mp18. The separation was achieved for fragments ranging in size from 31 to 520 bases in 65 minutes of analysis. A comparison with the GenBank sequence of M13mp18 revealed that the sequence information for 460 bases was obtained with an accuracy of $97.8 \%$.

\section{Sequencing using modified modular primers}

A reaction performed with a modular primer of one pentamer and three degenerate phosphorylated heptamers to prime the reaction at the $3^{\prime}$ position 2892 of M13mp18 was analyzed by CE. The pentamer was the front (3' primer end) module. The two middle and back oligonucleotides $\left(5^{\prime}\right.$ end of the primer) were $5^{\prime}$-phosphorylated and degenerate at the last two $3^{\prime}$ bases (19).

Figure 3 presents the separation of DNA sequencing fragments using this modified modular primer sequencing chemistry. Fragments ranging in size from 43 to 520 bases in length could be resolved with one base difference. The accuracy for 467 bases sequenced was $99.6 \%$ vs. the M13mp18 sequence (10). Thus, in Figures 2 and 3, the two chemistries yielded sequencing information for more than 460 bases in about one hour using CE with $4 \% \mathrm{~T}$ LPAA solutions. These promising results led us to determine the sequence of a portion of M13mp18.

Sequencing on M13mp18 singlestranded template 
Because of the availability of primers, SSB-hexamer primed chemistry was utilized to sequence a section of ssM13mp18 vector. Table 2 presents the sequence of the selected hexamer primers used for the sequencing reactions. Included in this table are the GC contents of the hexamers and the position on M13mp18 where the $3^{\prime}$ end of the front hexamer annealed. In separate studies, these hexamers were shown to yield moderately to highly successful sequencing reactions on slab gels with both radioactivity and fluorescence detection. With further experience it is anticipated that rules regarding the efficiency of hexamer priming will be established.

The sequencing results obtained using M13mp18 are summarized in Table 3 . The raw sequence data were analyzed using laboratory-developed sequencing software, followed by manual editing (see Base-Calling Software section). The average number of bases sequenced for these reactions was roughly 450 , and the average number of errors was 10 compared with the GenBank sequence (10), representing an average accuracy of $97.8 \%$. There are two main sources of error: the poor excitation of NAN dye label (ddG) by the 488-nm argon line laser and the deconvolution of the dye spectra by the sequencing software. Given that the maximum absorption of the NAN dye is $555 \mathrm{~nm}$, a second laser line in conjunction with an argon ion laser would have to be used to efficiently excite all four labeled dideoxynucleotides. Upon improved excitation of the NAN dye, the number of errors in the sequence call should decrease, thus improving accuracy further.

Nevertheless, the data represent initial promising results in the application of $\mathrm{CE}$ to primer walking DNA-sequencing strategies for genomic scale projects. Further developments in robotics, instrumentation and data analysis are required in order to apply $\mathrm{CE}$ routinely and effectively to DNA sequencing analysis. At present our laboratory is developing a multiple capillary array and appropriate robotics with a multiplex purification system in order to transform CE into a tool for largescale sequencing in combination with primer walking and other sequencing strategies.

\section{CONCLUSION}

M13mp18 was used as a model to assess the reliability of DNA sequencing using short oligonucleotide primer libraries and CE. The use of hexamers with SSB, together with modified modular primer sequencing chemistries, were successfully applied to CE with replaceable sieving matrices. These initial results provide promising evidence that these sequencing chemistries in combination with capillary electrophoresis have the potential to provide a fast, fully automated, closed-end system for DNA sequencing.

\section{ACKNOWLEDGMENTS}

The authors wish to acknowledge the DOE under the Human Genome Project Grant DE-FG02-90ER 60985 and the NIH under the project HG00023 for support of this work. The authors thank Drs. L. Ulanovsky and L. Kotler for the modified modular primer sequencing samples and their useful discussions. The authors would also like to thank Drs. F.W. Studier and M. Quesada for their suggestions and support. We are grateful to Dr. W. Goetzinger and L. Kesilman for the preparation of the capillary coatings. E. Carrilho thanks Conselho Nacional de Desenvolvimento Científico e Tecnológico $(\mathrm{CNPq})$, Brazil, for a scholarship. The authors also thank A.J. Berno for useful discussions regarding the base calling program. Finally, the authors acknowledge the assistance of Perkin-Elmer/Applied Biosystems Division in providing the separate labeled dideoxynucleotides. This is contribution No. 659 of the Barnett Institute.

\section{REFERENCES}

1.Bay, S., H. Starke, J.Z. Zhang, J.F. Elliot, L.D. Coulson and N.J. Dovichi. 1994. Capillary gel electrophoresis for DNA sequencing of a template from the malaria genome. J. Cap. Elec. 1:121-126.

2.Berno A.J. 1996. A graph-theoretic approach to the analysis of DNA sequencing data. Genome Research (In press).

3.Best, N., E. Arriaga, D.Y. Chen and N.J. Dovichi. 1994. Separation of fragments up to
570 bases in length by use of $6 \% \mathrm{~T}$ non-crosslinked polyacrylamide for DNA sequencing in capillary electrophoresis. Anal. Chem. 66:4063-4067.

4.Brumley Jr., R.L. and L.M. Smith. 1991. Rapid DNA sequencing by horizontal ultrathin gel electrophoresis. Nucleic Acids Res. 19:4121-4126.

5.Carson, S., A.S. Cohen, A. Belenkii, M.C. Ruiz-Martinez, J. Berka and B.L. Karger. 1993. DNA sequencing by capillary electrophoresis: Use of a two-laser-two-window intensified diode array detection system. Anal. Chem. 65:3219-3224.

6.Chase, J.W. and K.R. Williams. 1986. Single-stranded DNA binding proteins required for DNA replication. Ann. Rev. Biochem. 55:103-136.

7.Cohen, A. S., D. R. Najarian, A. Paulus, A. Guttman, J.A. Smith and B.L. Karger. 1988. Rapid separation and purification of oligonucleotides by high-performance capillary gel electrophoresis. Proc. Natl. Acad. Sci. 85:9660-9663.

8.Demorest, D.M. 1993. U.S. Patent No. 5264101

9.Fung, E. N. and E.S. Yeung. 1995. High speed DNA sequencing by using mixed poly (ethylene oxide) solutions in uncoated capillary columns. Anal. Chem. 67:1913-1919.

10.GenBank ${ }^{\circledR}$ Accession No. X02513.

11.Guttman, A., A. S. Cohen, D. N. Heiger and B. L. Karger. 1990. Analytical and micropreparative ultrahigh resolution of oligonucleotides by polacrylamide gel high-performance capillary electrophoresis. Anal. Chem. 62:137-141.

12.Hjerten, S. 1985. High-performance electrophoresis. Elimination of electroendosmosis and solute adsorption. J. Chromatogr. 347:191-198.

13.Holmberg, A., G. Fry and M. Uhlen. 1994. Automatic preparation of DNA templates for sequencing on the $\mathrm{ABI}$ catalyst robotic workstation, p. 139-145. In M.D. Adams, C. Fields, J.C. Venter (Eds.), Automated DNA Sequencing and Analysis. Academic Press, London.

14.Hunkeler, D. 1991. Mechanism and kinetics of the persulfate-initiated polymerization of acrylamide. Macromolecules 24:2160-2171.

15.Kambara, H. and S. Takahashi. 1993. Multiple sheathflow capillary array DNA analyser. Nature 361:565-566.

16.Karger, B.L., Y.-H. Chu and F. Foret. 1995. Capillary electrophoresis of proteins and nucleic acids. Ann. Rev. Biophys. Biomolec. Struct. 24:579-678.

17.Kieleczawa, J., J.J. Dunn and F.W. Studier. 1992. DNA sequencing by primer walking with strings of contiguous hexamers. Science 258:1787-1791.

18. Kotler, L.E., I.A. Sobolev and L. Ulanovsky. 1994. DNA sequencing: Modular primers for automated walking. BioTechniques. 17:554559.

19.Kotler, L.E., D. Zevin-Sonkin, I.A. Sobolev, A.D. Beskin and L.E. Ulanovsky. 1993. DNA sequencing-modular primers assembled from a library of hexamers or pentamers. Proc. Natl. Acad. Sci. U.S.A. 90:4241-4245.

20.Kowalczykowski, S.C., D.G. Bear and P.H. vonHippel. 1981. In P.D. Bayer (Ed.), The 
Enzymes, 3rd ed. v.14. Academic Press, New York, p. 373.

21.Krauss, G., H Sindermann, U. Schomburg and G. Maass. 1981. Escherichia coli singlestrand deoxyribonucleic acid binding protein: Stability, specificity, and kinetics of complexes with oligonucleotides and deoxyribonucleic acids. Biochemistry 20:5346-5352.

22.Luckey, J.A. and L.M. Smith. 1993. Optimization of electric field strength for DNA sequencing in capillary gel electrophoresis. Anal. Chem. 65:2841-2850.

23.Martin-Gallardo, A., J. Lamerdin and A. Carrano. 1994. Shot-gun sequencing, p.3741. In M.D. Adams, C. Fields, J.C. Venter, (Eds.), Automated DNA Sequencing and Analysis. Academic Press, London.

24.Mathies, R. A. and X.C. Huang. 1992. Capillary array electrophoresis: an approach to high-speed, high-throughput DNA sequencing. Nature 359:167-169.

25.McCombie, W. R. and J. Kieleczawa. 1994. Automated DNA sequencing using 4-color fluorescent detection of reactions primed with hexamer strings. BioTechniques. 17:574-579.

26.O'Keefee, T.J., S.G. Kieffer-Higgins, M.H. Hinzmann, A.J. Christopher, M.J. McCann, S.J. Gordon, J.L. Valle and G.M. Church. 1994. Operation of a 96 pin synthesizer for DNA sequencing and PCR. In Genome Sequencing Analysis Conference VI, Hilton Head, SC, September 17-21. Abstract C-32.

27.Press, W.H., B.P. Flannery, S.A. Teukolsky and W.T. Vetterling. 1986. Numerical Recipes: The Art of Scientific Computing. Cambridge University Press, Cambridge, England.

28.Qingbo, L. and E.S. Yeung. 1995. Evaluation of the potential of a charge-injection device for DNA sequencing by multiplexed capillary electrophoresis. Applied Spectroscopy 49: 825-833

29.Ruiz-Martinez, M.C. 1995. Capillary Electrophoresis: A Practical Analytical Tool for DNA Sequencing. Ph.D. Thesis, Northeastern University.

30.Ruiz-Martinez, M.C., J. Berka, A. Belenkii, F. Foret, A.W. Miller and B.L. Karger. 1993. DNA sequencing by capillary electrophoresis with replaceable linear polyacrylamide and laser induced fluorescence detection. Anal. Chem. 65:2851-2858.

31.Sambrook, J., E.F. Fritsch and T. Maniatis. 1989. Molecular Cloning: A Laboratory Manual. Cold Spring Harbor Laboratory Press, Cold Spring Harbor, NY. Appendix B.16.

32.Slightom, J.L., D.R. Siemieniak, L.C. Sieu, B.F. Koop and L. Hood. 1994. Nulceotide sequence analysis of $77.7 \mathrm{~kb}$ of human $\mathrm{V} \beta \mathrm{T}$-cell receptor gene locus: direct primer-walking using cosmid template DNAs. Genomics 20:149-168.

33.Stegemann, J., C. Schwager, H. Ertle, N. Hewitt, H. Voss, J. Zimmerman and W. Ansorge. 1991. High speed on-line DNA sequencing on ultrathin slab gels. Nucleic Acids Res. 19:675-676.

34.Studier, F.W. 1989. A strategy for high-volume sequencing of cosmids DNAs: random and directed priming with a library of oligonucleotides. Proc. Natl. Acad. Sci. USA 86: 6917-6919.

35.Swerdlow, H., K.E. Dew-Jager, K. Brady, R.
Grey, N.J. Dovichi and R. Gesteland. 1992. Stability of capillary gels for automated sequencing of DNA. Electrophoresis 13:475-483.

36.Szybalski, W. 1993. From the double-helix to novel approaches to the sequencing of large genomes. Gene 135:279-290.

37.Wilson, R., R. Ainscough, K. Anderson, C Baynes, M. Berks, J. Bonfield, J. Burton, M. Connell et. al. 1994. 2.2 Mb of contiguous nucleotide sequence from chromosome III of C. elegans. Nature 368:32-38.

Received 20 September 1995; accepted 30 November 1995.

Address correspondence to:

Barry L. Karger

Barnett Institute

Northeastern University

Boston, MA 02115, USA

Internet: bakarger@lynx.dac.neu.edu 